\title{
The Study of the Library Mobile Service Pattern
}

\author{
Zhiyin Yang $^{\mathrm{a}}$ and Jiakun $\mathrm{Hu}^{\mathrm{b}}$ \\ Information and Technology College, Jilin Agricultural University, Jilin, China \\ a23133124@qq.com, b942357462@qq.com
}

Keywords: Library; Mobile Service; Pattern

\begin{abstract}
As the technology developing, the number of the users of portable mobile terminals is increasing, under which circumstance the theory and the practical application study about library mobile information service come into being. In this paper, the connotation, the development status quo of library mobile services were analyzed, and the mobile library service model is put forward.
\end{abstract}

\section{Introduction}

The technology revolutionizing, the Internet and the mobile radio communications quickly developing, digital resource becomes the significant academic resource for us day by day. The hand-held mobile device like cell phones, laptops, and electronic readers gradually becoming common, and versatile, helping users to get library resources at anytime at anywhere through the mobile device is the urgent task to make libraries keep pace with the time.

Smart phones, the appearance and popularity of e-readers and tablet computers, heralds the society toward a new era -- the era of mobile computing. Mobile computing is a new technology whose development is along with the mobile communication, the Internet, the data base, and the distributed computation. Mobile computing will make providing the information server useful, accurate, timely information to the customers at anytime, anyplace a simple and easy thing, which has greatly changed people's life. The advent of the era of mobile computing not only poses challenges to library, but also has brought opportunities for development. How to improve library service in the era of mobile computing has become what the library people mainly think about.

\section{The Deeper Meaning of Library Mobile Service}

The Mobile Library Service, with the modern information technology, achieves two-sided communication by means of wireless network, using the network communicating and setting up library information resource database. The information includes all kinds of e-resources, like wap website visiting, cell phone messages and so on, aiming to build a knowledge platform, providing ubiquitous mobile library services. Let the reader get any information they want in any place conveniently, breakthrough the limitation of time and space to serve the readers better. The rapid development of computer information technology, mobile communication technology, the realization of the mobile library provides technical basis, the library also therefore had a bigger development space.

The Features of Library Mobility. Mobile library services access to information resources at anytime, anywhere, beyond the traditional library space and time limit and constraints. Users can never leave home, at any time through the wireless network interconnection, download and read access to the library network space resources, according to the characteristics of mobile service aaa that ANYONE (something) (ANYWHEN) at any time, any place (ANYWERE) can connect wireless network, through the mobile terminal in real-time access to information resources.

Due to the real-time network connection, the user can get real-time interactive communication with a librarian. A user can be in the outside, through the communication software or message boards to library reference service, also can undertake advance through the hand-held device and renew the self-service, manifests the service interaction, which not only improves the efficiency of library service, also saves the time of the reader, letting the users and librarians to realize real-time communication hyperspace more important and to be closer to the users and librarians. 
If library mobile service wants to broaden the user, it must learn passively into the library, making the user passively accept the knowledge or information. Libraries can take the initiative to send and subscribe the related resources users regularly through the network. Users can receive information via mobile device at anytime and anywhere, completing mobile access to information resource, browse and storage. The user will have more initiative and informality.

Users can get personalized services by their own interests, and also, can achieve the resources reading, researching, downloading, as well as costum-making through the mobile stage. With the attracting of library intentional services and individual resources, users will take apart in this more positively.

The library mobile service can extend beyond the library, satisfying the users' needs far away from the library. Moreover, the multimedia features of Library mobile services can meet some vulnerable groups by the needs of the library. For some instances, the disabled can have the book-indoor-borrowing service by sending the messages; the "storytelling" foundation on cell phones can also satisfy the needs of those whose eyesight is poor; the game-reading can provoke teenagers' reading interest.

Because of the people-oriented, fair and equal characteristics of information resource sharing, the user from the geographical space, binding status, can be shared via mobile devices, mobile information resources, truly information disclosure, information equality, narrowing the digital gap.

The Contents of Library Mobile Service. The prospective of library service revolves around the customers, and its principle is being universal and equal. The contents should also be based on users' needs, while its basic demand is to enhance users' satisfaction. Basing on this, the library mobile service should put users' mobile information needs the first place. Currently, our country's library mobile information service mainly includes:

The notice of library service. This includes the brief introduction about library service and foundation, the opening and closing time of library, the transaction of borrowing card, the researching of newly arrival books and the brief introduction of users' service information.

The register and maintain of users' account. Users register and revise their personal information by logging in the library server through mobile devices. At the same time, they can check the booklist they borrow, the returning time and renew the book they want.

The checking and pre-borrowing of books. The user can have the required books near the library in the library, such as the required books has not lent by registration information for pre loan service.

Information reminding and subscribing. Information reminding includes expiration reminding, the pre-subscribed reminding, which excludes the personal helps and does not have the limit of time and space; information subscribing The subscription refers to the RSS information push service of the personalized needs of users, the user subscription information regularly, sent to the user's mobile device oriented.

Reporting the loss of application cards. The reader through the mobile communication terminal, timely report the loss for the loss of the card, so as not to delay the timing of unnecessary loss.

Consult and feedback. The traditional library provides consulting through sending Email to users, and users have to turn their network data on and finish it on the Internet. The mobile library users can submit their problems anytime, the answer of which will be sent back after solved, so that users can communicate and consult conveniently.

\section{The Current Situation of Library Mobile Service}

Through the researching of the domestic public library and university library network survey and literature we found that the overall penetration rate and the quality of Library Mobile Services in China are relatively low: since 2003 the Beijing Institute of Technology found the first library mobile service, libraries that can offer such services are so few and most of them lie in the developed area; the forms of the services are too monotonous, most of which are in the forms of sending massages to readers for offering borrowing service. From the point of view of literatures, the overall number of literature since 2008 showed a significant growth trend, especially in the last 
two years as well. Clearly, the domestic study towards library mobile information service gradually springs up. Additionally, after the study about the paper's contents, we can find it mainly focused on the introduction about the domestic and alien library mobile service current situation, the case analysis and the prospects.

Visible, mobile library services in China in terms of actual service delivery or from the aspects of theoretical research, are at the exploratory stage, there are some problems, need to continue to develop, practice, enrich and modify.

Along with the mobile library service practice in depth, China is also a trend of the mobile library service mode theory. But the understanding of our library services to the mobile library mode is still in the traditional library, mobile library service mode that is just extension of the traditional library service model and development, but in the service function, innovative service means; in the connotation of mobile library service mode, performance and other key dimensions of proposition has not yet formed a unified understanding.

The future society will be the ubiquitous information society, and the ultimate goal of all people is to use information anytime anywhere safely. Because the current theoretical research and practical application of mobile libraries in China are in the initial stage, there are still a lot problems to be solved, such as mobile reading copyright, researching on mobile service development and ubiquitous information society under the environment of the mobile library mobile service. The application of domestic mobile library is very extensive, and many libraries provide mobile library services, while most of the services are transformed from the traditional library service, without innovating brand new services basing on the features of library and users' needs, making the mobile library lack of attraction. We should strengthen the theoretical research of mobile library, the construction of a new generation of mobile service system to meet the needs of users. With the extension of mobile library services, copyright issues brought by mobile library are also a major issue. How to effectively carry out users' authentication in a mobile environment, to carry out in-depth development of mobile library services are problems must be considered.

\section{The Construction of Library Mobile Model}

The development of the network of mobile service system can be seen everywhere, for its convenient and efficient advantages in all walks of life. Therefore, the library management should also keep pace with the times, make full use of the advantages of the network, and break through the traditional management mode of the barrier. According to the needs of readers, we should establish their own network management platform, improving the library service management. Based on mobile Internet library management service is not just simply moving the traditional service function, but also according to the needs of users of new mining work can more advanced service management. As the picture shows below:

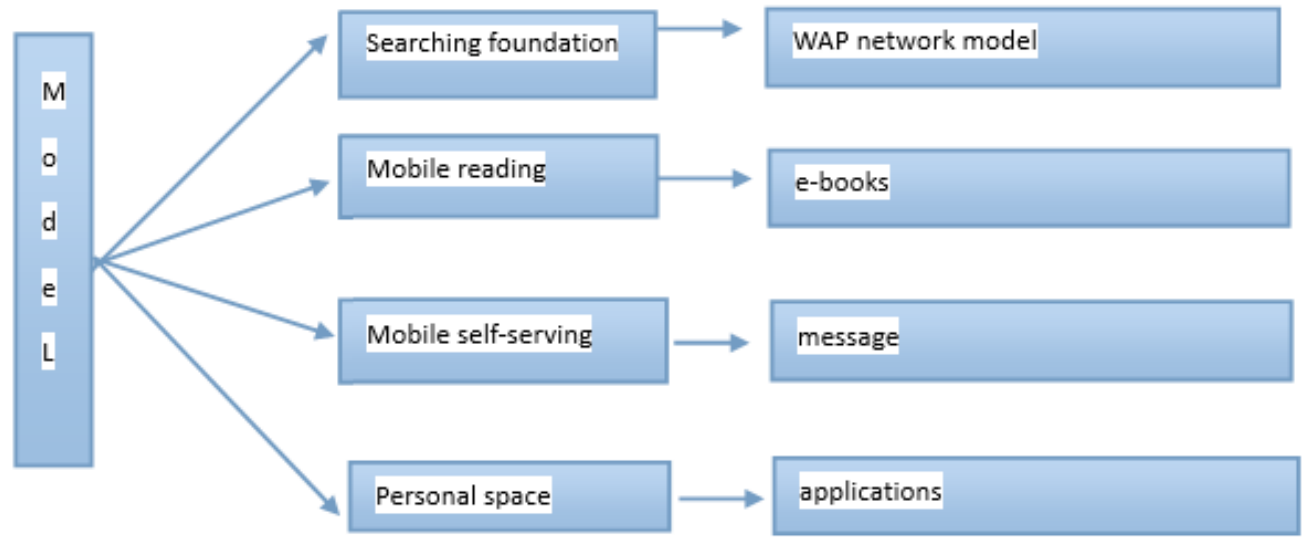

Figure 1. The mobile library service model 
Retrieving Foundation. The main function of the mobile search is realized on the books of the efficient, accurate researching, to meet the needs of readers and library management personnel management. This function, being realized by the mobile Internet search engine technology, stores the library resources and other related resources in the system database, connecting them to the database through the searching engine. In addition to the convenience researching, it also realizes the highly integral sharing between library resources and the Internet.

The retrieval function is realized by service website WAP model. WAP technology is an open technology, is the international standard of the connection between mobile application and the Internet. This technology can be introduced into the library service of university library information to the mobile terminal. WAP library can let readers access to the library homepage through the mobile phone, realize a book query, borrowing, renewing and other functions. There are a variety of articles, information browsing and data download being offered on this stage, which highly convenient the reads. At present, there are many colleges and universities are one the way of developing on the mobile phone library, and the using effect is good.

The construction of mobile website is to facilitate the users to browse and query book information whenever and wherever possible, understanding the latest information and dynamic library, quick accessing to and retrieving of literature resources. Download journals and multimedia information, WAP website platform library can publish audio, video, e-books and pictures of various carriers to users information. Demanding oriented to build powerful WAP server, the server provides timely update and maintenance. User comments and discussion page, pay attention to service of humanization and individuation, providing users and librarian interactive platform.

Mobile Reading. Mobile reading service is based on the mobile terminal equipment, therefore, requirements for terminal equipment with high resolution. This function can implement the reader no matter they are on campus, dining room, home, cars and so on. The realization of this function needs to consider whether the text format suitable for the mobile phone. The terminal equipment and manufacturers will read the resources into a format suitable for the terminal on the use of the technology. Set the privilege management of library resources library for readers to download or purchase for management.

The mobile reading is realized through the e-books reading. Through the mobile terminal, readers can use mobile phone or Ipad online or have them downloaded to the terminal to read. The library can also put good multimedia data resources, such as music, pictures and video on the WAP website, for mobile phone and other mobile terminal online to look and download.

Mobile Self-serving. Mobile library management service to achieve the user complete service function previously required to the library to complete the equipment, such as books management, membership management and so on. Self service function is the key of realizing the seamless mobile service platform through the library and the library system, library collection inquiries, booking, renew, borrow expiration reminder, consulting such as self-service mobile services.

Mobile self-serving is realized by message service. With the rapid development of mobile communication technology and mobile phone penetration rate, in the realization of interpersonal communication function, the propagation characteristics of mobile phone text messages, making it the first world have the basic conditions as the mass media. This can help broaden message service from a monotonous agency to the common citizens. Apart from finishing the exchanging and transforming of personal information, it will gradually take part in the public, which shows a good chance for the public information service unit like the library to develop new projects. This kind of service, compared with the Internet online service now, let users have greater independence and randomness. Users only need to retrieve the request and search through the mobile phone to send the request and let the servers to analyze.

For those people who don't have the identity to log in the Internet, messages are still the way they can get library service at the mobile age. Libraries should dig into the potential of message service, reform more traditional services, and extend it to voice service, making them take more and richer contents and foundations, so that the library service can reach a higher level of initiative, universality and proximity. 
Personal Space. The mobile library service can realize such function, set up their own independent space for the readers. Readers can enter through authentication. In the mobile space, readers can view their own reservation management, borrowing history records, loan information. According to the reader's library can push subscription library dynamic, recommending books, academic journals seminar, column information.

Personal space through the client application service model to achieve the client application is the product of mobile library, digital library and mobile terminal application integration. In the client application service mode, mobile users do not need to consider services who develop, who provides, and access ways; to avoid duplication, enter the URL of the tedious operation burden; strong expansibility, rich in content, powerful mobile client application has brought hitherto unknown network experience for the user, so on behalf of the current mobile library technology is the most advanced, most powerful as a service model.

\section{Conclusion}

The construction and study of library mobile service play an important role of setting up common libraries, provoking the development of information society. The mobile library service is bound to be the significant mean of future library serving. We should use of library resources, and offer readers more those original data resources, which is also the initial part of future library service system construction. In the resource construction should focus on all media resources, cross screen, multi network integration services. Standard construction of resources construction and service in the building will also become the focus of the recent mobile digital library service system construction.

\section{References}

[1] Y.F. Zhang: Library Mobile Information Service Research (MS., Xiangtan University, China 2013), p.9.

[2] K.Y. Xv, X.H. Liu: Library and Information Job, (2010) No. 11, p.72.

[3] H.R. Hua: Journal of Hebei University of Economics, (2012) No.2, p.25.

[4] Y.S. Ji, Y.X. Li and W.L. Xue: Library Research, (2010) No. 22, p.9.

[5] Y.H. Mao: The Present Situation and Development Countermeasure of Mobile Information Service in China's Library (MS., Nanjing Agricultural University, 2011), p.35.

[6] Y.J. Guo: Hua Zhang, (2013) No.18, p.26.

[7] L. Xin: Mobile Library Service Mode Exploration (MS., Harbin Normal University, 2013), p.59

[8] Information on http:// www. ala.org /files/ content/starkweather.pdf

[9] Y.F. Zhang: Library Mobile Information Service Research (MS., Xiangtan University, China 2013), p.9.

[10] Y.Dai. Mobile Internet based Library Mobile Service Exploration (Guangdong University of Water and Power Technology, 2013), p.5 